\title{
Effect of morning exercise in sunlight on the sleep-wake cycle in adolescents
}

\author{
Ana Paula Leão Maia, Ivanise Cortez de Sousa and Carolina Virginia Macêdo de Azevedo \\ Universidade Federal do Rio Grande do Norte, Natal, RN, Brazil
}

\begin{abstract}
A delay in bedtime occurs in adolescence compared with childhood. However, the early waking that morning school hours impose leads to partial sleep deprivation. Although exposure to light is the most important regulator of circadian rhythm in mammals, physical exercise influences circadian synchronization. To assess the effect of morning physical exercise in sunlight on the sleep-wake cycle (SWC) in adolescents, 160 first- and second-year high-school students were exposed to classes in their usual classroom (Group C) or in a swimming pool exposed to sunlight (Group E) while physically exercising (EE; i.e., swimming) or resting (EL). At baseline, we applied Health and Sleep and Horne \& Ostberg chronotype assessment questionnaires. One week later and during the intervention, we applied the Sleep Diary and Karolinska Sleepiness Scale. During the intervention we observed no changes in bedtime, time in bed and in indices of irregularity of bedtime and wake-up time. The changes observed in wake-up time (i.e., a delay in the EE group on Saturday), sleep quality (i.e., an improvement), and sleepiness (i.e., an increase) were also observed in the control group, discarding an intervention effect. We suggest that morning physical exercise in sunlight had no effect on SWC parameters, sleep quality, or daytime sleepiness, possibly because of the large irregularity in the SWC between weekdays and weekends in adolescent students as well as the low frequency and duration of exercise during the intervention. Therefore, studies that evaluate a higher frequency or duration of exercise are needed to assess its effect on the SWC in adolescents. Keywords: adolescents, physical exercise, sleep-wake cycle, partial sleep deprivation, school time.
\end{abstract}

Received 15 April 2011; received in revised form 5 July 2011; accepted 7 July 2011. Available online 29 December 2011

\section{Introduction}

Adolescence is characterized by innumerable transformations such as a delay in bedtimes and wakeup times compared with childhood and adulthood and a greater need for sleep compared with adulthood. This delay has long been considered a psychosocial modification that results from the lifestyle during this phase, characterized by increased socialization (Carskadon, 2002; Carskadon \& Acebo, 2002) and reinforced by other social factors such as decreased parental discipline with regard to bedtime (Carskadon, 2002), extracurricular employment (Teixeira et al. 2007), and increased school activities (Carskadon, 2002).

Nevertheless, the delay in bedtimes during adolescence is linked not only to social factors but also to biological factors (Andrade, Benedito-Silva, Domenice, Arnhold, \& Menna-Barreto, 1993; Wolfson et al., 2002; Carskadon,

Ana Paula Leão Maia, Ivanise Cortez de Sousa, Carolina Virginia Macêdo de Azevedo. Laboratório de Cronobiologia, Departamento de Fisiologia, Universidade Federal do Rio Grande do Norte-Natal/RN. Correspondence regarding this article should be directed to: Carolina Azevedo, Laboratório de Cronobiologia; Departamento de Fisiologia, Centro de Biociências, Universidade Federal do Rio Grande do Norte, Caixa Postal 1511, CEP 59078970, Natal/RN, Brazil. Phone: +5584 3215-3409. Fax: +5584 3211-9205. E-mail: carolina@cb.ufrn.br
Acebo, \& Jenni, 2004). Among the biological factors, evidence indicates that changes occur in the circadian and homeostatic processes of sleep-wake cycle (SWC) regulation during puberty (Carskadon et al., 2004; Taylor, Jenni, Acebo, \& Carskadon, 2005; Carskadon, 2011). With regard to the circadian component, a delay in the circadian pattern has been proposed, possibly caused by an increase in the endogenous period reflected by a delay in the secretion of melatonin and other rhythms. Additionally, a change in sensitivity to light may occur that decreases in the morning and increases later in the day.

However, the morning school schedule is in contrast to the delay (i.e., adolescents go to bed and wake up earlier during the week). Consequently, they sleep less and exhibit partial sleep deprivation and irregular wake-up times between weekdays and weekends (Taillard, Philip, \& Bioulac, 1999; Saarenpää-Heikkila, Rintahaka, Laupalla, \& Koivikko, 2000; Louzada \& Menna-Barreto, 2003). This irregular SWC and daily loss of sleep lead to an increase in daytime sleepiness and a decline in school performance compared with more regular sleep patterns (Wolfson \& Carskadon, 1998; Acebo \& Carskadon, 2002).

This pattern has been observed in several countries, confirming that adolescents who study in the morning represent a portion of the population who may face 
health problems caused by sleep deprivation (Wolfson \& Carskadon, 1998; Epstein, Chilag, \& Lavie, 1998; Andrade \& Menna-Barreto, 2002). Therefore, interventions are necessary within the school setting. Despite the positive effects of later school start times (Epstein et al., 1998; Wahlstrom, 2002), implementation of such modification is complex and involves not only students and teachers but also several aspects of social life associated with school. As an alternative intervention, educational programs (Cortesi, Giannotti, Sebastiani, Bruni, \& Ottaviano, 2004; Sousa, Araújo, \& Azevedo, 2007; Cain, Gradisar, \& Moseley, 2011) have been evaluated in school settings to inform students about sleep to prevent the negative effects of sleep deprivation on school days. To minimize the delay in sleep in adolescents, few studies have evaluated the effect of SWC synchronizers in a school environment (Sousa, 2009; Hansen, Janssen, Schiff, Zee, \& Dubocovich, 2005). Evaluation of these factors can expand the intervention alternatives within a school context.

The main synchronizing factor of the SWC is the environmental light-dark cycle (Czeisler et al., 1986, 1989; Czeisler \& Khalsa, 2000; Youngstedt, Kripke, \& Elliott, 2002). The effect of this cycle on the SWC has been assessed by numerous studies. Pulses of bright light generate phase delays and advances in the circadian rhythm of humans (Honma, Honma, \& Wada, 1987; Czeisler \& Khalsa, 2000; Samková, Vondrasova, Hájek, \& Illnerova, 1997). These effects vary according to the time of their occurrence in the organism (Khalsa, Jewett, Cajochen, \& Czeisler, 2003). Regardless of bedtime preference (i.e., chronotype), individuals who are exposed to early morning sunlight undergo advances in sleep onset of $30 \mathrm{~min}$ for each hour of light exposure (Roenneberg, Wirtz-Justice, \& Merrow, 2003), although exposure to light between early evening and during the night promotes delays in sleep onset (Khalsa et al., 2003).

Although light exposure is considered the most important regulator of the circadian system in mammals (Meijer, Michel, \& Vansteensel, 2007), studies of rodents and humans indicate that physical exercise (PE) influences circadian synchronization (Mistlberger $\&$ Skene, 2005) because of the ability to modify the temporal relationship between the organism and the environment, acting as a synchronizer of biological oscillators (Back, Fortes, Santos, Tambelli, MennaBarreto, \& Louzada, 2007). Physical exercise triggers a phase delay between the middle and end of the resting phase in humans (Barger, Wright, Hughes, \& Czeisler, 2004; Van Reeth et al., 1994), but controversy exists regarding the time at which the circadian system responds by triggering phase advances (Atkinson, Edwards, Reilly, \& Waterhouse, 2007; Buxton, Lee, L'Hermite-Baleriaux, Turek, \& Van Cauter, 2003; Miyazaki, Hashimoto, Masubuchi, Honma, \& Honma, 2001; Piercy \& Lack, 1988). Buxton et al. (2003) observed phase advances in response to high-intensity PE performed in the early evening, whereas Piercy \& Lack (1988) reported a phase advance in temperature rhythm and a shorter delay to the first episode of rapideye-movement sleep in response to morning PE (6:00 AM-8:00 AM) in individuals exposed to sunlight compared with PE performed in the late afternoon and early evening (5:00 PM-7:00 PM).

In addition to these effects, $\mathrm{PE}$ is related to the promotion of health and well-being. Sherrill, Kotchou, \& Quan (1998) observed a significantly lower prevalence of sleep problems and daily napping episodes in individuals who engaged in PE compared to subjects who were sedentary, which was associated with the beneficial effects of PE on sleep quality and self-esteem. Additionally, the regular practice of high levels of physical activity is positively related to sleep quality and psychological function in adolescents (Brand et al., 2010). It is also related to a lower frequency of drug use and a higher propensity to participate in health-promoting behaviors (Delisle, Werch, Wong, Bian, \& Weiler, 2010).

The evaluation of the application of PE associated with morning sunlight represents one possible intervention in the school setting, due to the response of the circadian system to light and PE. Intervention in the school environment assessed by the effect of sunlight exposure in the early hours of the morning 5 days per week on the SWC in adolescents shows a tendency to advance bedtime (Sousa, 2009). In contrast, exposure to intense artificial light in the morning did not affect nocturnal sleep in adolescents or decrease daytime sleepiness during weekdays (Hansen et al., 2005).

However, given that the impact of morning $\mathrm{PE}$ on the SWC has not been assessed in adolescents (Mistlberger \& Skene, 2005), more investigations are needed. Thus, we evaluated the effect of morning PE in sunlight on the SWC in adolescents. We expected to observe an advance in bedtimes and wake-up times, an increase in time in bed, an improvement in sleep quality, and a reduction in daytime sleepiness.

\section{Methods}

\section{Subjects}

This study was approved by the institutional ethics committee (protocol no. 006/2007, UFRN). The sample was composed of 160 high-school students aged 14-17 years (16 \pm .7 years); $55 \%$ were girls and $45 \%$ were boys. Considering housing conditions, the majority $(61 \%)$ of the students shared a house with three to four persons. Approximately $47 \%$ of the students slept alone in a room, and $33 \%$ slept with only one other person. Regarding the level of education of the person who was financially responsible for the family, 50\% had completed graduate courses. 
Exclusion criteria included students who did not submit an informed consent form signed by their parents or legal guardians or did not correctly complete the questionnaires, as well as the inability to swim and health problems (respiratory and psychosomatic).

\section{Apparatus}

Initially, a general characterization of the students was conducted with respect to sleep habits and chronotype using the Health and Sleep (Mathias, Sanchez, \& Andrade, 2006) and Horne-Ostberg questionnaires, respectively. Moreover, the SWC was assessed at two stages (baseline and during the intervention) using the Sleep Diary with regard to the following variables: bedtime, wake-up time, time spent in bed, an index of bedtime and wake-up time irregularity assessed by the standard deviation of bedtime and wakeup time, and frequency, time, and duration of napping. Daytime sleepiness was assessed by the Karolinska Sleepiness Scale (KSS). Alertness was assessed by the Psychomotor Vigilance Test (PVT). Students also completed a self-assessment questionnaire that assessed the effect of the intervention of the study on their SWC. This self-assessment ascertained which discipline kept them most alert in the early morning hours.

\section{Procedure}

Three groups were assessed: control group $(C, n=68$; the students attended class in their usual classroom under illumination of $142.3 \pm 4.7$ lux) and two experimental groups exposed to sunlight $(34.190 \pm 137 \mathrm{lux})$, one of which engaged in physical exercise (experimental exercise [EE] group, $n=49$ ) and the other which remained at rest (experimental light [EL] group, $n=43$ ).

The SWC of each group was evaluated for two consecutive weeks. The first week was considered baseline (Stage 1). The intervention was done during the second week on two days (Monday and Wednesday) in the students' first class (between 7:45 AM and 8:30 AM), which substituted for their usual class.

Physical exercise consisted of a swimming class in an outdoor pool between 7:45 AM and 8:30 AM. Swimming involved different styles such as the crawl and breaststroke for $30 \mathrm{~min}$ followed by a 30 -s rest interval. Before swimming, the students engaged in muscle-stretching exercises. During the procedure, we assessed light intensity at eye level using a digital light meter (ICEL, LD-500).

\section{Statistical analysis}

Bedtime (BT), wake-up time (WT), time in bed (TB), indices of bedtime (BI) and wake-up time irregularities (WI), sleep quality (SQ), and reaction time (RT) were compared between stages using repeated-measures analysis of variance (ANOVA). The three groups were compared with the two stages as the repeated measures.
Also, the seven weekdays were considered repeated measures for the analysis of BT, WT, TB and SQ, and the $2 \mathrm{~h}$ of the day tested were the repeated measures for RT analysis. Moreover, daytime sleepiness assessed by the KSS was evaluated using repeated-measures analysis of variance. However, missing data as a result of incomplete questionnaires precluded the application of ANOVA using the two stages, the seven days and the $6 \mathrm{~h} /$ day as repeated measures. Thus, a similar design was applied for each day of the week, considering the two stages and $6 \mathrm{~h} /$ day as the repeated measures. Tukey test was used for post hoc analysis.

The frequency of naps during the week and weekend was compared between groups and stages using the $\chi^{2}$ test. The beginning, end, and duration of napping were analyzed by factorial ANOVA, with the two groups, two stages, and two types of days of week (week and weekend) as factors. All tests were conducted using Statistica software (StatSoft); significance level was established at 5\%.

\section{Results}

Bedtime $\left(F_{1,105}=.35, p>.05\right), \mathrm{WT}\left(F_{1,97}=.86, p>\right.$ $.05)$, indices of BT irregularity $\left(F_{1,143}=.48, p>.05\right)$ and WT irregularity $\left(F_{1,145}=2.63, p>.05\right)$, and TB $\left(F_{1,98}=\right.$ $1.66, p>.05$ ) were not different between stages (Figure 1). However, repeated-measures ANOVA revealed an interaction between stage, day, and group for WT $\left(F_{12,582}\right.$ $=1.94, p<.05)$, indicating distinct differences between Stage 1 and 2. During Stage 2, students in the EE and C groups woke up later on Saturday ( $p<.05$, Tukey test). The C group woke up earlier on Monday $(p<.05$, Tukey test). This difference was not related to the intervention because it was also observed in the $\mathrm{C}$ group.

Furthermore, the groups did not differ with regard to BT $\left(F_{2,105}=1.65, p>.05\right)$ and TB $\left(F_{2,98}=.07, p>\right.$ $.05)$ in both stages $\left(F_{1,105}=.35, p>.05\right)$. With regard to WT, the EE group woke up later than the other groups $\left(F_{2,97}=7.87, p<.05\right)$ with no differences between stages $\left(F_{2,97}=.80, p>.05\right)$, ruling out the possibility of an interventional effect.

Differences were found in BT $\left(F_{6,630}=26.73, p<\right.$ $.05)$, WT $\left(F_{6,582}=122.91, p<.05\right)$, and TB $\left(F_{6,588}=16.31\right.$, $p<.05$ ) between weekdays and weekend days (Figure 1). Throughout the week, students went to bed later on Saturdays ( $p<.05$, Tukey test). They had later BT on Fridays compared with Mondays and Wednesdays and later BT on Sundays compared with Tuesdays $(p<.05$, Tukey test). They woke up later on Sundays, followed by Saturdays and then Mondays compared with the other days of the week ( $p<.05$, Tukey test). EE and EL groups did not exhibit differences between Mondays and the other days of the week (Tuesday-Friday, $p>$ .05 , Tukey test). Students spent more TB on Saturday and Friday nights compared with the other nights of the 


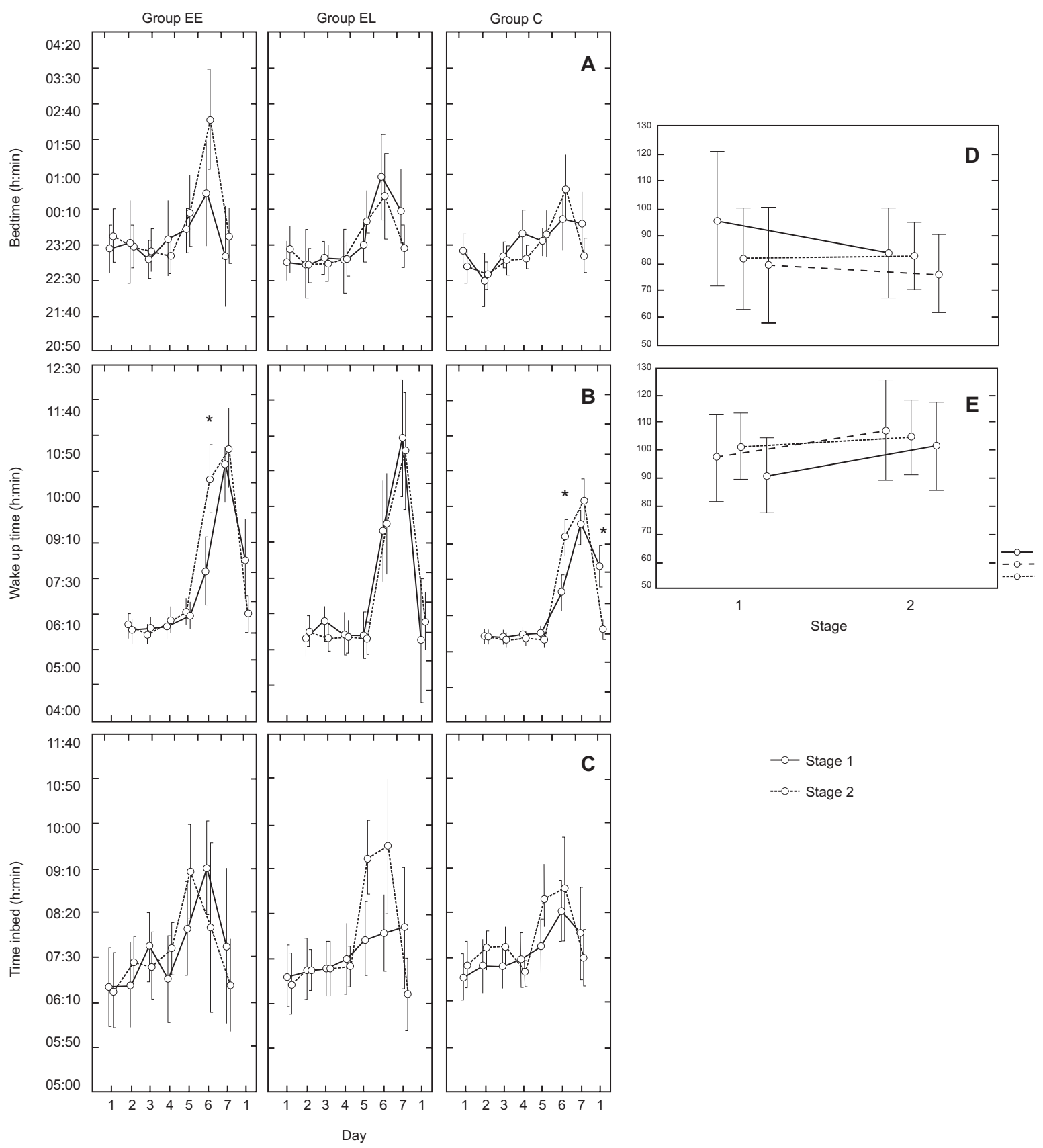

Figure 1. Bedtime (A), wake-up time (B), time in bed (C), irregularity of bedtime (D), and irregularity of wake-up time (E) in the experimental exercise (EE), experimental light (EL), and control (C) groups (mean $\pm 95 \%$ confidence interval) during the week and weekend in Stage 1 and 2. Day 1, Monday; Day 2, Tuesday; Day 3, Wednesday; Day 4, Thursday; Day 5, Friday; Day 6, Saturday; Day 7, Sunday. * $p<.05$ (Tukey test).

week $(p<.05$, Tukey test). Repeated-measures ANOVA revealed an interaction between day and stage for BT $\left(F_{6,630}=2.19, p<.05\right)$ and WT $\left(F_{6,588}=4.84, p<.05\right)$, but this was not observed for the group factor (BT, $F_{12,630}$ $=1.30, p>.05$; WT, $\left.F_{12,588}=1.71, p>.05\right)$. Thus, the variations in the occurrence of these differences during the week and on weekend days were similar in all groups and were not linked to interventional effects.

The beginning $\left(F_{1,593}=.26, p>.05\right)$ and end $\left(F_{1,593}\right.$ $=.18, p>.05)$ of napping did not vary between stages (Table 1). Duration of napping increased during Stage 2
$\left(F_{1,593}=4.12, p<.05\right)$ with no differences between groups $\left(F_{2,593}=.33, p>.05\right)$. With regard to the percentage of students who napped, differences were found between groups during the week and weekend $\left(p<.05, \chi^{2}\right.$ test), with no differences between stages ( $p>.05, \chi^{2}$ test).

Sleep quality improved during Stage $2\left(F_{1,92}=11.39\right.$, $p<.05)$ in all groups $\left(F_{2,92}=1.88, p>.05\right)$. Differences were found between days of the week $\left(F_{6,552}=4.53, p<\right.$ .05 ; Figure 2), with better sleep quality on Friday nights compared with Monday, Tuesday, and Wednesday nights $(p<.05$, Tukey test). The interaction between 
Table 1. Napping characteristics (mean $\pm \mathrm{SD}$ ) in the control $(\mathrm{C})$, experimental exercise (EE), and experimental light (EL) groups

\begin{tabular}{|c|c|c|c|c|c|c|}
\hline & \multicolumn{2}{|c|}{ EE Group } & \multicolumn{2}{|c|}{ EL Group } & \multicolumn{2}{|c|}{ C Group } \\
\hline & Stage 1 & Stage 2 & Stage 1 & Stage 2 & Stage 1 & Stage 2 \\
\hline \multicolumn{7}{|l|}{$\begin{array}{l}\text { Weekday } \\
\text { Nap (h:min } \pm \text { min) }\end{array}$} \\
\hline Start & $14: 22 \pm 80$ & $14: 06 \pm 96$ & $13: 43 \pm 177$ & $14: 01 \pm 151$ & $14: 02 \pm 120$ & $13: 29 \pm 75$ \\
\hline End & $16: 03 \pm 81$ & $15: 52 \pm 105$ & $15: 21 \pm 204$ & $15: 50 \pm 166$ & $15: 44 \pm 136$ & $15: 26 \pm 182$ \\
\hline Duration & $1: 42 \pm 62$ & $1: 46 \pm 65$ & $1: 37 \pm 66$ & $1: 49 \pm 56$ & $1: 41 \pm 70$ & $1: 58 \pm 80$ \\
\hline Frequency $(\%)$ & $16 \%{ }^{\mathrm{a}}$ & $12 \%{ }^{\mathrm{b}}$ & $11 \% \mathrm{o}^{\mathrm{a}}$ & $11 \% \mathrm{o}^{\mathrm{b}}$ & $19 \% \%^{\mathrm{a}}$ & $14 \%{ }^{\mathrm{b}}$ \\
\hline \multicolumn{7}{|l|}{ Weekend } \\
\hline \multicolumn{7}{|l|}{ Nap (h:min \pm min) } \\
\hline Start & $14: 01 \pm 127$ & $13: 15 \pm 195$ & $13: 42 \pm 208$ & $14: 42 \pm 130$ & $13: 28 \pm 170$ & $12: 59 \pm 185$ \\
\hline End & $15: 51 \pm 150$ & $15: 16 \pm 206$ & $14: 57 \pm 229$ & $16: 22 \pm 138$ & $15: 07 \pm 171$ & $15: 01 \pm 191$ \\
\hline Duration & $1: 49 \pm 91$ & $2: 00 \pm 73$ & $1: 14 \pm 40$ & $1: 40 \pm 51$ & $1: 39 \pm 51$ & $2: 02 \pm 56$ \\
\hline Frequency $(\%)$ & $4 \%{ }^{\mathrm{c}}$ & $4 \%{ }^{\mathrm{d}}$ & $2 \%{ }^{c}$ & $2 \%^{\mathrm{d}}$ & $3 \%^{\mathrm{c}}$ & $3 \%^{\mathrm{d}}$ \\
\hline
\end{tabular}

a,b,c,dSimilar letters represent $p<.05\left(\chi^{2}\right.$ test). Stage $1=$ Stage 2: Week $\left(\chi_{(2)}^{2}=2.897, p>.05\right)$, Weekend $\left(\chi_{(2)}^{2}=.179, p>.05\right)$. $\mathrm{SD}$, standard deviation.

group and day $\left(F_{12,552}=1.96, p<.05\right)$ was associated with distinct differences in this pattern during the days between groups that were not related to interventional effects. No interaction was found between day, group, and stage $\left(F_{12,552}=.87, p>.05\right)$.

Daytime sleepiness was not different between stages $(p>.05$, ANOVA) with the exception of Monday when an increase was observed at 11:30 AM during Stage $2(p<$
.05 , Tukey test $)$ in all groups $\left(F_{2,44}=.27, p>.05\right)$. A general decrease was observed on Saturday during Stage $2\left(F_{1,28}=\right.$ $5.84, p<.05)$. Sleepiness varied during the day $(p<.05$, ANOVA), showing a general daytime pattern characterized by increased alertness at 8:30 AM, 11:30 AM, and 2:30 PM and more sleepiness at WT and BT during the week and on the weekend $(p<.05$, Tukey test). These differences were less pronounced on weekends (Figure 3).

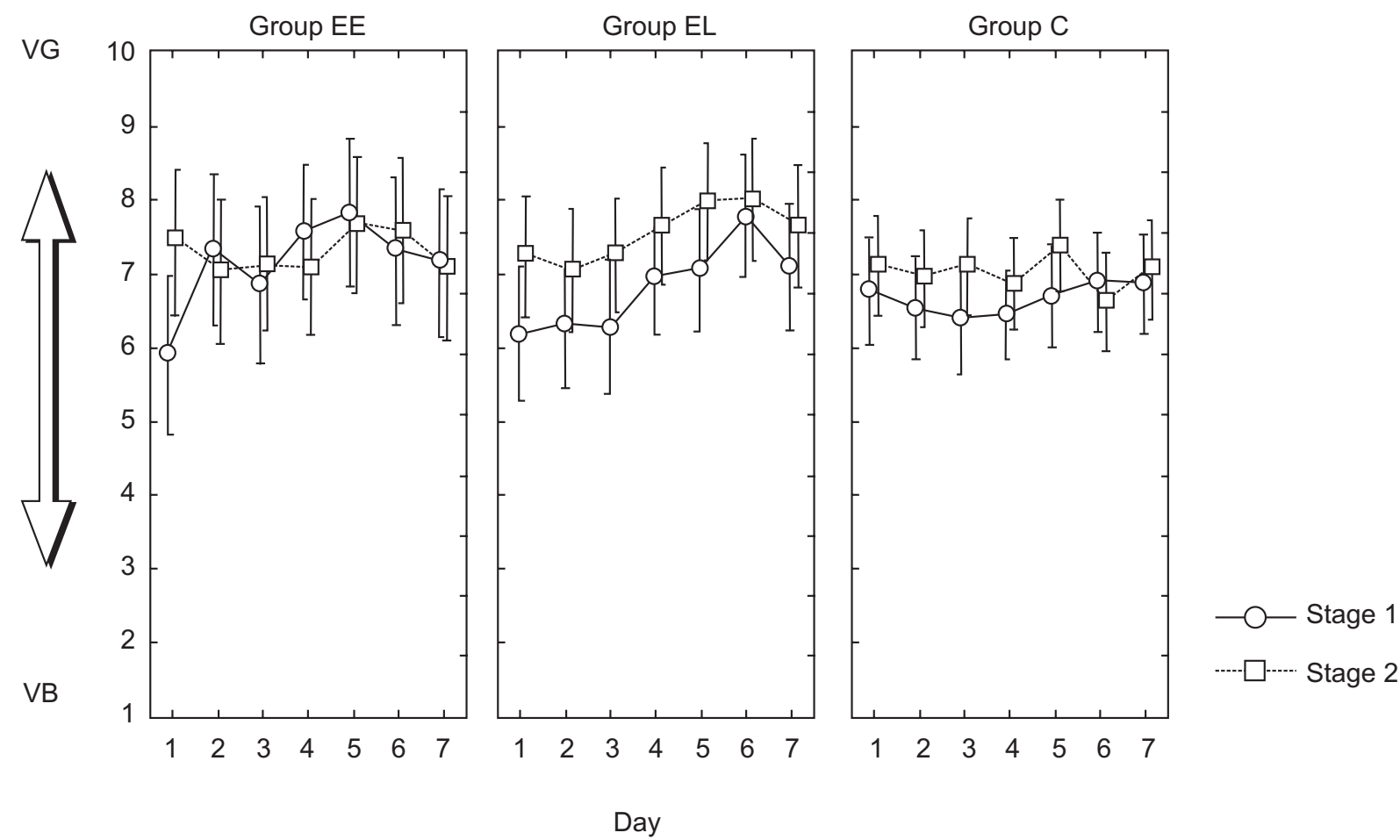

Figure 2. Quality of sleep (mean $\pm 95 \%$ confidence interval) in the EE, EL, and C groups during the week and weekend during Stage 1 and 2. Day 1, Monday; Day 2, Tuesday; Day 3, Wednesday; Day 4, Thursday; Day 5, Friday; Day 6, Saturday; Day 7, Sunday. 


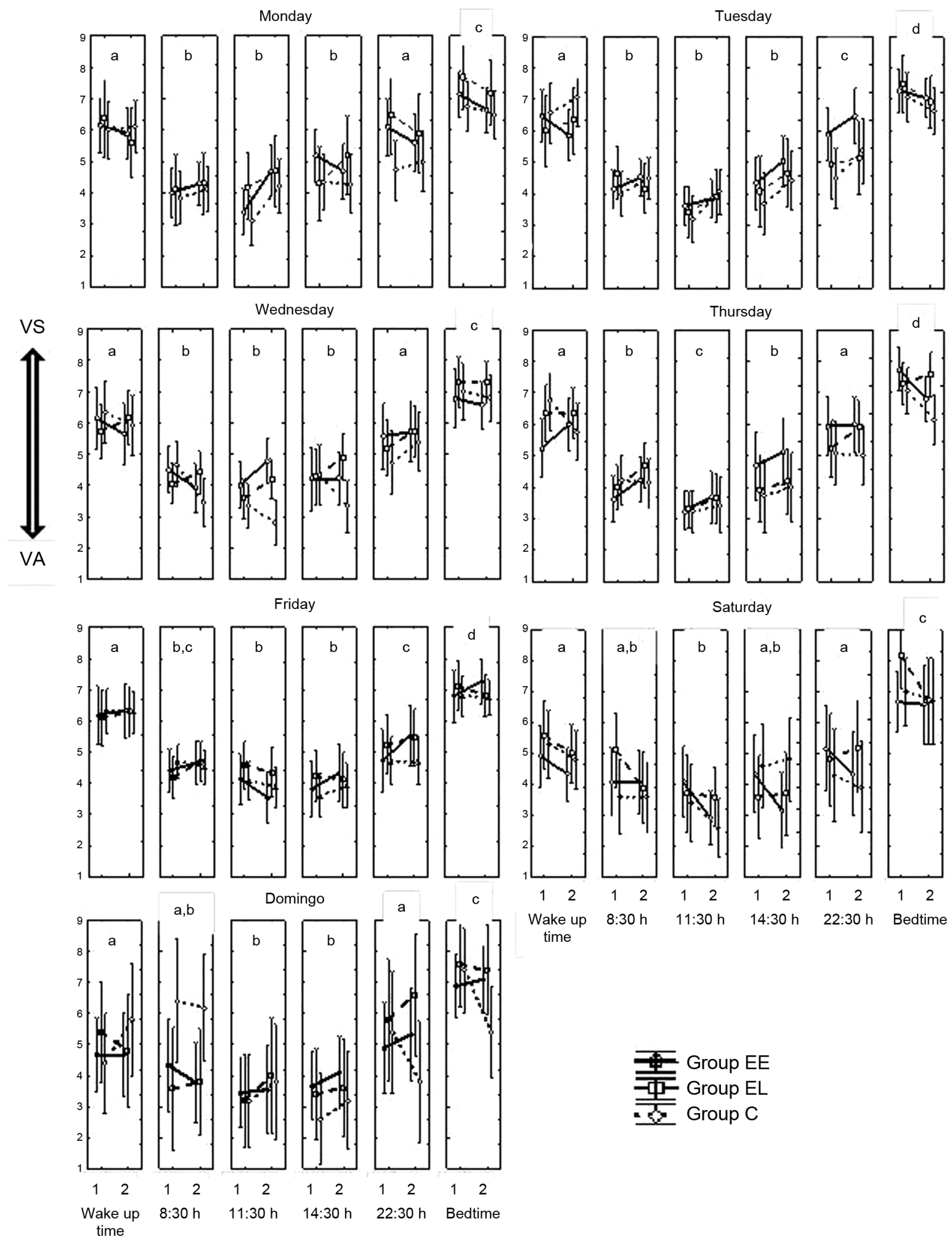

Figure 3. Sleepiness during daytime hours (mean $\pm 95 \%$ confidence interval) measured using the Karolinska Sleepiness Scale

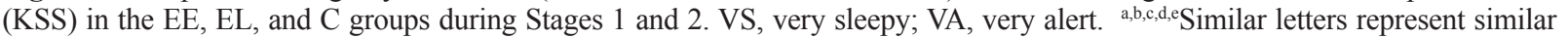
hours $(p>.05$, Tukey comparison between hours). 
Reaction time was not different between stages $\left(F_{1,32}=2.27, p>.05\right.$; Figure 4$)$, although a trend was found toward differences between groups $\left(F_{2,32}=3.29\right.$, $p=.05)$. The $\mathrm{C}$ group had shorter reaction times than the EE group $\left(p<.05\right.$, Tukey test) during both stages $\left(F_{2,32}\right.$ $=.97, p>.05)$.

With regard to the subjective effects of the physical education classes, $55.6 \%$ of the students reported that physical education was the discipline that would keep them most alert during the early morning hours $\left(\chi^{2}=\right.$ $1.25, p>.05)$.

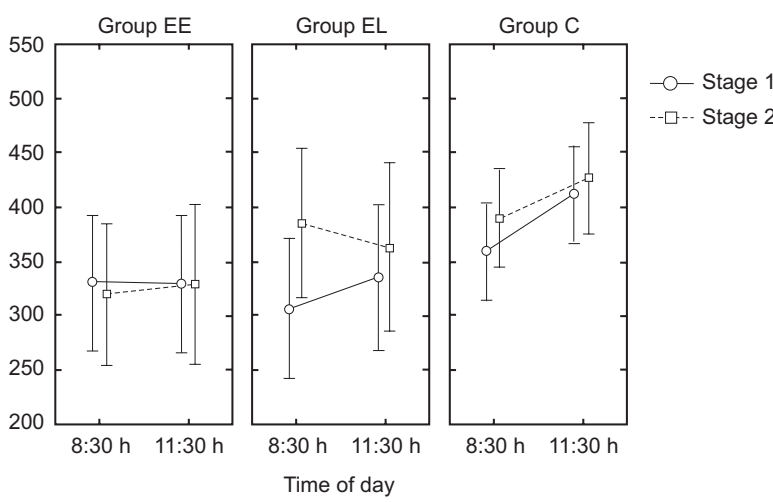

Figure 4. Reaction time (mean $\pm 95 \%$ confidence interval) measured using the Psychomotor Vigilance Test (PVT) between Stages 1 and 2 in the EE, EL, and C groups.

\section{Discussion}

The SWC profiles that we found among students at baseline were similar to those observed in Brazilians (Andrade et al., 1993; Louzada \& Menna-Barreto, 2003; Sousa et al., 2007), Americans (Shinkoda, Matsumoto, Park, \& Nagashima, 2000; Iglowstein, Jenni, Mollinari, \& Largo, 2003), and Italians (Giannotti \& Cortesi, 2002). The students showed later and longer nocturnal sleep on weekends and earlier and shorter nocturnal sleep on weekdays, confirming the SWC irregularity characteristic of students who study in the morning (Andrade et al., 1993; Wolfson \& Carskadon, 1998; Shinkoda et al., 2000; Giannotti \& Cortesi, 2002; Iglowstein et al., 2003). These characteristics contribute to the difficulties that adolescents have in going to bed earlier in addition to the greater demands of high school compared with primary school, resulting in poorer nocturnal sleep quality and duration (Shinkoda et al., 2000). Thus, on weekdays, students exhibit partial sleep deprivation, which has serious consequences for physical, emotional, intellectual, psychological, and social development (Giannotti \& Cortesi, 2002).

During the intervention we observed no changes in $\mathrm{BT}, \mathrm{TB}$ and in indices of BT and WT irregularity. The delay in WT observed in the EE group on Saturday also occurred in the $\mathrm{C}$ group. Thus, no interventional effect can be assumed. Our results differ from those obtained by Piercy \& Lack (1988) who assessed the effect of PE performed in sunlight in adults at least five times per week during a 3-week interval (running 8-12 km for 35$55 \mathrm{~min} /$ day), in which phase advances were observed in response to morning PE. Lack of effects of PE observed in the present study may be associated with the lower frequency or duration of exercise during the intervention (30 min of swimming for 2 days of 1 week). Our results are similar to the findings of Moog \& Hildebrant (1986) in which no changes were observed in the SWC in response to $15 \mathrm{~min}$ of early morning PE (cycling) for 2 days over a interval of 2 weeks. Youngstedt et al. (2002) found no effect of PE on the response to bright light pulses in a protocol that used high-intensity exercise (cycling on an ergometer for $3 \mathrm{~h}$ in one night). Despite the high intensity of exercise, the authors argued that this may be insufficient to elicit effects because the subjects had extremely high fitness levels.

Another factor that may contribute to the lack of effects may be the conditions under which the study was performed. As stated by Back et al. (2007), a synchronizer effect of PE is usually observed in protocols in which the subjects are in a laboratory setting under controlled conditions where the influence of photic and nonphotic synchronizers is reduced (Barger et al., 2004, Buxton et al., 2003; Miyazaki et al., 2001; Van Reeth et al., 1994) With regard to sleep quality, an improvement was found during Stage 2 in all groups, indicating no interventional effect. The absence of effects of PE on sleep quality is similar to observations in college students (Lund, Reider, Whiting, \& Prichard, 2010) but dissimilar to observations in high school students (Brand et al., 2010; Delisle et al., 2010). The present results may also be related to the frequency or duration of PE. Studies that have shown a positive association between $\mathrm{PE}$ and sleep quality in adolescents used high levels of vigorous exercise in students (Delisle et al., 2010) and athletes (Brand et al., 2010). The higher levels of sleep quality on weekend nights in all groups were also observed by Sousa et al. (2007) in adolescents and may be associated with the absence of the pressures of morning school schedules.

Our hypothesis that the present intervention and sunlight would promote decreases in daytime sleepiness and changes in the other variables (frequency, beginning, end, and duration of napping and reaction time) was not confirmed. An increase in sleepiness was observed during Stage 2, but this was observed in all of the groups, ruling out the possibility of an interventional effect. Daytime sleepiness exhibited a daily profile characterized by greater alertness at 8:30 AM, 11:30 AM, and 2:30 PM and greater sleepiness at wake-up time and bedtime. On weekends, adolescents felt more alert, similar to the observations of Andrade et al. (1993), Teixeira et al. (2007), and Sousa et al. (2007). 
The absence of the expected effects of the intervention on the SWC may be associated with the frequency or duration of PE or the type of intervention. Students were evaluated in a school setting, and we did not monitor or control other factors that may have impacted the results such as evening habits that lead to light exposure near bedtime and caffeine intake that may delay bedtimes, thus increasing the irregularities in BT and WT during the week and on weekends. Students exhibited irregularities of BT and WT of nearly 80 min and $100 \mathrm{~min}$, respectively. An intervention with a longer frequency or duration may be necessary to elicit changes in the large irregularity of sleep schedules and lead to the expected effect on sleep duration and sleep quality and, consequently, daytime sleepiness. Another limitation of our study was incomplete questionnaire data, which may have contributed to the difficulties in the statistical analysis.

Absence of the expected interventional effects on the SWC and the lack of knowledge about the neural mechanisms involved in social, nonphotic synchronization do not necessarily diminish the importance of social factors in the regulation of the relationship between human rhythms and the photic synchronizer, the natural light-dark cycle (Back et al., 2007). Therefore, because of the synchronizing effect of PE on the SWC and the subjective effects of physical education classes reported by the students as the discipline that keeps them most alert early in the morning, more extensive studies on the effects of PE in this age group are needed. This can be achieved by applying more frequent interventions with a greater duration and photic and nonphotic controls to promote a better assessment of the effects of PE on the SWC.

In summary, PE in the morning in sunlight had no effect on SWC parameters, sleep quality, or daytime sleepiness in adolescent students, possibly because of the large irregularity in the SWC between weekdays and weekends associated with the low frequency/duration of exercise during the intervention.

\section{Acknowledgements}

Special thanks are given to the students who participated in this study and the school staff. We also thank Master's students Aline Silva Belísio and Jane Carla de Souza and Dr. Fernando Louzada, Dr. Alexandre Menezes, and Dr. John Araújo for their contribution to this research. This study was financially supported by CAPES and UFRN.

\section{References}

Acebo, C., \& Carskadon, M. A. (2002). Influence of irregular sleep patterns on waking behavior. In Carskadon, M.A. (Ed.), Adolescent sleep patterns: Biological, social, and psychological influences (pp. 220-235). Cambridge: Cambridge University Press.
Andrade, M., \& Menna-Barreto, L. (2002). Sleep patterns of high school students living in São Paulo, Brazil. In Carskadon, M.A (Ed.), Adolescent sleep patterns: Biological, social, and psychological influences (pp. 118-131). Cambridge: Cambridge University Press.

Andrade, M., Benedito-Silva, A. A., Domenice, S., Arnhold, I. J., \& Menna-Barreto, L. (1993). Sleep characteristics of adolescents: A longitudinal study. Journal of Adolescent Health, 14, 401-406.

Atkinson, G., Edwards, B., Reilly, T., \& Waterhouse, J. (2007) Exercise as a synchroniser of human circadian rhythms: An update and discussion of the methodological problems. European Journal of Applied Physiology, 99, 331-341.

Back, F. L., Fortes F. S., Santos, E. H. R., Tambelli, R., MennaBarreto, L. S., \& Louzada, F. M. (2007). Sincronização não-fótica: $\mathrm{O}$ efeito do exercício físico aeróbio. Revista Brasileira Medicina do Esporte, 13(2), 1-5.

Barger, L. K., Wright, K. P., Jr., Hughes, R. J., \& Czeisler, C. A. (2004). Daily exercise facilitates phase delays of circadian melatonin rhythm in very dim light. American Journal of Physiology: Regulatory, Integrative and Comparative Physiology, 286, R1077-R1084.

Brand, S. Gerber, M., Back, J., Hatzinger, M., Pühse, U., \& HolsboerTrachsler, E. (2010). High exercise levels are related to favorable sleep patterns and psychological functioning in adolescents: A comparison of athletes and controls. Journal of Adolescent Health, 46, 133-141.

Buxton, O., Lee, C. W., L'Hermite-Baleriaux, M., Turek, F. W., \& Van Cauter, E. (2003). Exercise elicits phase shifts and acute alterations of melatonin that vary with circadian phase. American Journal of Physiology: Regulatory, Integrative and Comparative Physiology, 284, R714-R724.

Cain, N., Gradisar M., Moseley L. (2011). A motivational school-based intervention for adolescent sleep problems. Sleep Medicine, 12, 246-51.

Carskadon, M. A. (2002). Factors influencing sleep patterns of adolescents. In Carskadon, M. A. (Ed.), Adolescent sleep patterns: Biological, social, and psychological influences (pp. 4-26). Cambridge: Cambridge University Press.

Carskadon, M. A. (2011). Sleep in adolescents: The perfect storm. Pediatric Clinics of North America, 58, 637-647.

Carskadon, M. A., Acebo, C., \& Jenni, O. G. (2004). Regulation of adolescent sleep: Implications for behavior. In Dahl, R. E., \& Spear, L. P. (Eds.), Adolescent brain development: Vulnerabilities and opportunities (series title: Annals of the New York Academy of Sciences, vol. 1021) (pp. 276-291). New York: New York Academy of Sciences.

Carskadon, M. A., \& Acebo, C. (2002). Regulation of sleepiness in adolescents: Update, insights, and speculation. Sleep, 25(6), 606-614.

Cortesi, F., Giannoti, F., Sebastiani, T., Bruni, O., \& Ottaviano, S. (2004). Knowledge of sleep in Italian high school students: Pilottest of a school-based sleep educational program. Journal of Adolescent Health, 34, 344-351.

Czeisler, C. A., Allan, J. S., Strogatz, S. H., Ronda, J. M., Sánchez, R., Ríos, C. D. \& Kronauer, R. E. (1986). Bright light resets the human circadian pacemaker independent of the timing of the sleep-wake cycle. Science, 233(4764), 667-671.

Czeisler, C. A., Kronauer, R. E., Allan, J. S., Duffy, J. F., Jewett, M. E., Brown, E. N., Ronda, J. M. (1989). Bright light induction of strong (type 0) resetting of the human circadian pacemaker. Science, 244(4910), 1328-1333.

Czeisler, C. A., \& Khalsa, S. B. S. (2000). The human circadian timing system and sleep-wake regulation. In Kryger, M. H., Roth, T., \& Dement, W. C. (Eds.), Principles and practice of sleep medicine, 3rd edition (pp. 353-375). Philadelphia: W.B. Saunders.

Delisle, T. T., Werch, C. E., Wong, A. H., Bian, H., \& Weiler, R. (2010). Relationship between frequency and intensity of physical activity and health behaviors of adolescents. Journal of School Health, 80, 134-140.

Epstein, R., Chilag, N., \& Lavie, P. (1998). Starting times of school: Effects on daytime functioning of fifth-grade children in Israel. Sleep, 21, 250-256.

Giannotti, F., \& Cortesi, F. (2002). Sleep patterns and daytime function in adolescence: An epidemiological survey of an Italian high school student sample. In Carskadon, M. A. (Ed.), Adolescent sleep patterns: Biological, social, and psychological influences (pp. 132-147). Cambridge: Cambridge University Press.

Hansen, M., Janssen, I., Schiff, A., Zee, P. C., \& Dubocovich, M. L. 
(2005). The impact of school daily schedule on adolescent sleep. Pediatrics, 115, 1555-1561.

Honma, K., Honma, S., \& Wada, T. (1987). Phase-dependent shift of free-running human circadian rhythms in response to a single bright light pulse. Experientia, 43, 1205-1207.

Iglowstein, I., Jenni, O. G., Molinari, L., \& Largo, R. H. (2003). Sleep duration from infancy to adolescence: Reference values and generational trends. Pediatrics, 111(2), 302-307.

Khalsa, S. B., Jewett, M. E., Cajochen, C., \& Czeisler, C. A. (2003). A phase response curve to single bright light pulses in human subjects. Journal of Physiology, 549, 945-952.

Louzada, F. M., \& Menna-Barreto, L. (2003). Sleep-wake cycle expression in adolescence: Influences of social context. Biological Rhythm Research, 34(2), 129-136.

Lund, H. G., Reider, B. D., Whiting, A. B., \& Prichard, J. R. (2010). Sleep patterns and predictors of disturbed sleep in a large population of college students. Journal of Adolescent Health, 46, 124-132.

Mathias, A., Sanchez, R. P., \& Andrade, M. M. M. (2006). Incentivar hábitos de sono adequados: Um desafio para os educadores. In Pinho, S. Z., \& Saglietti J. R. C. (Eds.), Núcleos de ensino da Unesp (pp. 718-731). São Paulo: UNESP.

Meijer, J. H., Michel, S., \& Vansteensel, M. J. (2007). Processing of daily and seasonal light information in the mammalian circadian clock. General and Comparative Endocrinology, 152(2-3), 159-164.

Mistlberger, R. E., \& Skene, D. J. (2005). Nonphotic entrainment in humans? Journal of Biological Rhythms, 20(4), 339-352.

Miyazaki, T., Hashimoto, S., Masubuchi, S., Honma, S., \& Honma, K. I. (2001). Phase-advance shifts of human circadian pacemaker are accelerated by daytime physical exercise. American Journal of Physiology: Regulatory, Integrative and Comparative Physiology, 281, R197-R205.

Moog, R., \& Hildebrant, G. (1986). Comparison of different causes of masking effects. In Haider, M., Koller, M., \& Cerinka, R. (Eds.), Night and shiftwork: Longterm effects and their prevention (pp. 131-140). New York: Peter Lang.

Piercy, J., \& Lack, L. (1988). Daily exercise can shift the endogenous circadian phase. Journal of Sleep Research, 17, 393.

Roenneberg, T., Wirz-Justice, A., \& Merrow, M. (2003). Life between clocks: Daily temporal patterns of human chronotypes. Journal of Biological Rhythms, 18(1), 80-90.

Saarenpää-Heikkila, O. A., Rintahaka, P. J., Laupalla, P. J., \& Koivikko, M. (2000). Subjective daytime sleepiness and related predictors in Finnish schoolchildren. Sleep and Hypnosis, 2, 4.
Samková, L., Vondrasova, D., Hájek, I., \& Illnerova, H. (1997). A fixed morning awakening coupled with a low intensity light maintains a phase advanced of the human circadian system. Neuroscience Letters, 224, 21-24.

Sherrill, D. L., Kotchou, K., \& Quan, S. F. (1998). Association of physical activity and human sleep disorders. Archives of Internal Medicine, 158, 1894-1898.

Shinkoda, H., Matsumoto, K., Park, Y. M., \& Nagashima, H. (2000). Sleep-wake habits of schoolchildren according to grade. Psychiatry and Clinical Neurosciences, 54, 287-289.

Sousa, I. C., Araújo, J. F. \& Azevedo, C. V. M. (2007). The effect of a sleep hygiene education program on the sleep-wake cycle of Brazilian adolescent students. Sleep and Biological Rhythms, 5, 251-258.

Sousa, I. C. (2009). Estratégias para ajuste do ciclo vigília-sono de adolescentes aos horários escolares matutinos: A educação sobre o sono e a exposição à luz solar [unpublished doctoral thesis]. Universidade Federal do Rio Grande do Norte.

Taillard, J., Philip, P., \& Bioulac, B. (1999). Morningness/eveningness and the need for sleep. Journal of Sleep Research, 8, 291-295.

Taylor, D. J., Jenni, O. G., Acebo, C., Carskadon, M. A. (2005). Sleep tendency during extended wakefulness: Insights into adolescent sleep regulation and behavior. Sleep, 14(3), 239-244.

Teixeira, L. R., Lowden, A., Turte, S. L., Nagai, R., Moreno, C. R. C., Latorre, M. R., \& Fischer, F. M. (2007). Sleep and sleepiness among working and non-working high school evening students. Chronobiology International, 24, 99-113.

Van Reeth, O., Sturis, J., Byrne, M. M., Blackman, J. D., L'HermiteBalèriaux, M., Leproult, R., ... Van Cauter, E. (1994). Nocturnal exercise phase delays circadian rhythms of melatonin and thyrotrophin secretion in normal men. American Journal of Physiology, 266, E964-E974.

Wahlstrom, K. (2002). Changing times: Findings from the first longitudinal study of later high school start times. NASSP Bulletin, 86(633), 3-21.

Wolfson, A. R., \& Carskadon, M. A. (1998). Sleep schedules and daytime functioning in adolescents. Child Development, 69, 875-887.

Wolfson, A. R., Carskadon, M. A., Acebo, C., Seifer, R., Fallone, G., Labyak, S. E., \& Martin, J. L. (2002). Evidence for the validity of a sleep habits survey for adolescents. Sleep, 26(2), 213-216.

Youngstedt, S. D., Kripke, D. F., \& Elliott, J. A. (2002). Circadian phase-delaying effects of bright light alone and combined with exercise in humans. American Journal of Physiology: Regulatory, Integrative and Comparative Physiology, 282, R259-R266. 